\title{
Assessment of efficacy, safety, and tolerability of 4-n-butylresorcinol $0.3 \%$ cream: an Indian multicentric study on melasma
}

This article was published in the following Dove Press journal:

Clinical, Cosmetic and Investigational Dermatology

21 January 2016

Number of times this article has been viewed

\section{NT Madan Mohan' \\ Adarsh Gowda ${ }^{2}$ \\ Ashok Kumar Jaiswal' \\ BC Sharath Kumar ${ }^{2}$ \\ P Shilpashree' \\ Bilugumba Gangaboraiah ${ }^{3}$ \\ Manjula Shamanna ${ }^{4}$ \\ 'Department of Dermatology, Dr BR Ambedkar Medical College (BRAMC), Bangalore, Karnataka, India; ${ }^{2}$ Department of Dermatology, ${ }^{3}$ Department of Community Medicine, Kempegowda Institute of Medical Sciences (KIMS), Bangalore, Karnataka, India; ${ }^{4}$ Medical Services, Micro Labs Ltd, Bangalore, Karnataka, India}

Video abstract

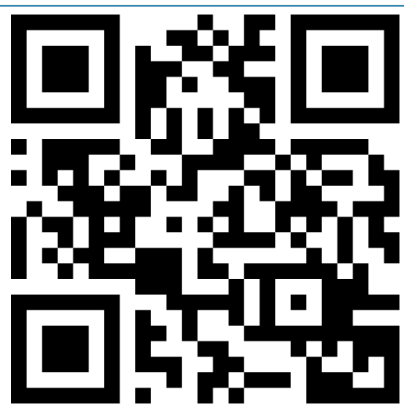

Point your SmartPhone at the code above. If you have a QR code reader the video abstract will appear. Or use: http://youtu.be/i0gF9h517HE

Correspondence: NT Madan Mohan Department of Dermatology, Dr BR Ambedkar Medical College (BRAMC), Kadugondanahalli, Bangalore 560045, Karnataka, India

Tel +9l 98450743 I6

Email mmblr123@gmail.com
Introduction: Melasma is one of the commonly reported pigmentory disorders in the Indian population. Numerous therapeutic modalities are available. However, very few have produced complete satisfactory response. $4-n$-Butylresorcinol $0.3 \%$ cream has recently been introduced in India as a new hypopigmenting agent. It is a resorcinol derivative and acts by inhibiting both tyrosinase and tyrosinase-related protein-1.

Objective: The available published literatures are with 4 - $n$-butylresorcinol $0.1 \%$ cream, and there is paucity of clinical studies with $4-n$-butylresorcinol $0.3 \%$ cream. Furthermore, considering the fact that Indian skin is more prone to irritation with hypopigmenting agents, our study explores the efficacy, safety, and tolerability of $4-n$-butylresorcinol $0.3 \%$ cream in Indian subjects with melasma.

Methods: Fifty-two subjects with melasma participated in this open-label, single arm, observational study. All the patients were advised twice daily application of 4- $n$-butylresorcinol $0.3 \%$ cream for 8 weeks over the areas of melasma. Assessment parameters included modified Melasma Area Severity Index (mMASI) score. Digital photographs of all the patients at baseline, week 4, and week 8 were taken. During this 8 -week study period, all the adverse events were observed and recorded.

Results: All the 52 subjects completed the study. Out of 52 subjects, $90.38 \%$ were females. The mean age of patients was $38.5 \pm 7.8$ years. Mean \pm standard error of MASI score measurements showed a significant decrease from baseline score of $14.73 \pm 0.59$ to $11.09 \pm 0.53$ after week $4(P<0.001)$ and $6.48 \pm 0.43$ at week $8(P<0.001)$. The digital photographs of the study subjects taken at week 4 and week 8 also showed decrease in melasma pigmentation compared to baseline photograph and correlated with the changes in the mMASI score. The treatment was well tolerated by all the study subjects. No adverse reactions were reported throughout the study period.

Conclusion: Our data suggest that the 4 - $n$-butylresorcinol $0.3 \%$ cream is safe, effective, and well tolerated in Indian patients with melasma.

Keywords: 4-n-butylresorcinol, melasma, topical treatment, tyrosinase inhibitors

\section{Introduction}

Melasma is the commonly reported pigmentory disorder in the Indian population. The word melasma is derived from the Greek word "melas" meaning black. It is an acquired bilateral symmetrical condition, presenting with often irregular, light to gray brown macules that are patchy with ill-defined margin, involving sun exposure area and is most commonly seen in women. ${ }^{1-3}$ Melasma is a multifactorial dermatological condition. The causative factors include ultraviolet A, ultraviolet B, contraceptive pills, antiepileptic medications, mild ovarian or thyroid dysfunction, certain cosmetics, genetic factors, 
malnutrition, liver dysfunction, $\mathrm{B}_{12}$ deficiency, etc. There is increased deposition of melanin in the epidermal and dermal layers or both in patients with melasma.,

\section{Types of melasma}

Melasma is broadly classified depending on pattern, depth, history. Table 1 depicts the different types of melasma. Wood's lamp examination is used to categorize melasma types (epidermal, dermal, mixed, and indeterminate type) based on the depth of the lesion. Furthermore, depending on the natural history of the lesions, melasma may also be classified into transient and persistent types, and three clinical patterns of distribution of the pigmentation may be recognized: centrofacial, malar, and mandibular depending on the pattern.

\section{Pharmacotherapy}

Studies have established that tyrosinase is a key enzyme in the synthesis of melanin and plays a pivotal role as a rate-limiting enzyme in the conversion of tyrosinase to dihydroxyphenylalanine. Therefore, it is essential for any hypopigmenting agent to act as an inhibitor of tyrosinase. Numerous therapeutic modalities such as hydroquinone, kojic acid, and arbutin are available. These agents are usually used along with retinoic acid, topical corticosteroids, or laser treatment. However, very few have produced complete satisfactory response. ${ }^{6}$ Newer options in the management of melasma are essential, and 4- $n$-butylresorcinol is the latest addition to therapeutic armamentarium.

Table I Different types of melasma ${ }^{15-17}$

\begin{tabular}{|c|c|}
\hline \multicolumn{2}{|c|}{ Depending on pattern } \\
\hline $\begin{array}{l}\text { Centrofacial } \\
\text { (most common) }\end{array}$ & $\begin{array}{l}\text { Involves the cheeks, nose, forehead, upper lip, } \\
\text { and chin. }\end{array}$ \\
\hline Malar & Involves the cheeks and nose. \\
\hline Mandibular & Involves the ramus of the mandible. \\
\hline \multicolumn{2}{|c|}{ Depending on depth } \\
\hline $\begin{array}{l}\text { Epidermal type } \\
\text { (most common) }\end{array}$ & $\begin{array}{l}\text { Pigmentation appears more intense under } \\
\text { Wood's lamp examination. }\end{array}$ \\
\hline Dermal type & $\begin{array}{l}\text { Pigmentation is not intensified with Wood's light. } \\
\text { The pigmentation is because of melanophages in } \\
\text { the dermal layer. }\end{array}$ \\
\hline Mixed type & $\begin{array}{l}\text { Wood's light intensifies pigmentation in some } \\
\text { areas, while other areas remain unchanged. } \\
\text { The pigmentation is due to increased epidermal } \\
\text { melanin as well as dermal melanophages. }\end{array}$ \\
\hline \multicolumn{2}{|c|}{ Depending on history } \\
\hline Transient type & $\begin{array}{l}\text { Disappears within I year of cessation of hormonal } \\
\text { stimuli like pregnancy or oral contraceptive pills. }\end{array}$ \\
\hline Persistent type & $\begin{array}{l}\text { Continues to be present more than I year after } \\
\text { the hormonal stimulus is removed and is caused } \\
\text { by the action of UV rays and other factors. }\end{array}$ \\
\hline
\end{tabular}

Abbreviation: UV, ultraviolet.

\section{4-n-Butylresorcinol}

4-n-Butylresorcinol, a resorcinol derivative, inhibits both tyrosinase and tyrosinase-related protein-1 (TRP-1). Hypopigmenting action of 4- $n$-butylresorcinol was first reported in 1995, and subsequent in vitro and in vivo studies have documented its hypopigmenting efficacy. In the MelanoDerm skin model culture, 4- $n$-butylresorcinol has proven to be the most potent hypopigmenting agent when compared to kojic acid, hydroquinone, and arbutin. Furthermore, the biochemical assay on inhibition of human tyrosinase activity has revealed the superiority of 4- $n$-butylresorcinol over other hypopigmenting agents. ${ }^{6}$

In a study, Okubo et $\mathrm{al}^{7}$ reported the inhibitory effect of 4- $n$-butylresorcinol on cultured $\mathrm{B}_{16}$ melanoma cells and established the role of 4- $n$-butylresorcinol on tyrosinase activity with no cytotoxicity. This paved the way for newer in vivo studies which established more evidences on the activity of both tyrosinase and TRP-1. ${ }^{7}$

Numerous in vivo and in vitro studies, biochemical assays, and clinical studies show 4- $n$-butylresorcinol to be very potent, effective, and safe in melasma. However, all the published studies of 4- $n$-butylresorcinol have shown the hypopigmenting efficacy, safety, and tolerability with the $0.1 \%$ cream, but there is paucity of clinical studies that used the $0.3 \%$ cream. Furthermore, ethnic differences in skin reactivity have been explored through the years, leading to the clinical hypothesis that Asian skin is more reactive than black skin and Caucasian skin. ${ }^{8}$ Considering these, and the fact that $4-n$-butylresorcinol $0.3 \%$ cream is available for the first time in India, we explored the efficacy, safety, and tolerability of 4- $n$-butylresorcinol $0.3 \%$ cream in Indian patients with melasma.

\section{Materials and methods}

A multicentric, open-label, single arm study was conducted in two premier medical colleges of Bangalore, India. The study centers were Dermatology Departments of Dr BR Ambedkar Medical College and Kempegowda Institute of Medical Sciences, Bangalore, India.

This study was conducted according to the protocol and in accordance with ethical guidelines. The study was conducted at each trial site after receiving approval from the KIMS Institutional Ethics Committee, Bangalore and the Institution Ethics Committee, Dr. B.R. Ambedkar Medical College, Bangalore. The study was registered in Clinical Trial Registry of India (CTRI) (CTRI/2015/04/005697).

The subjects were subjected to Wood's lamp light examination for diagnosis of epidermal melasma, and this was 


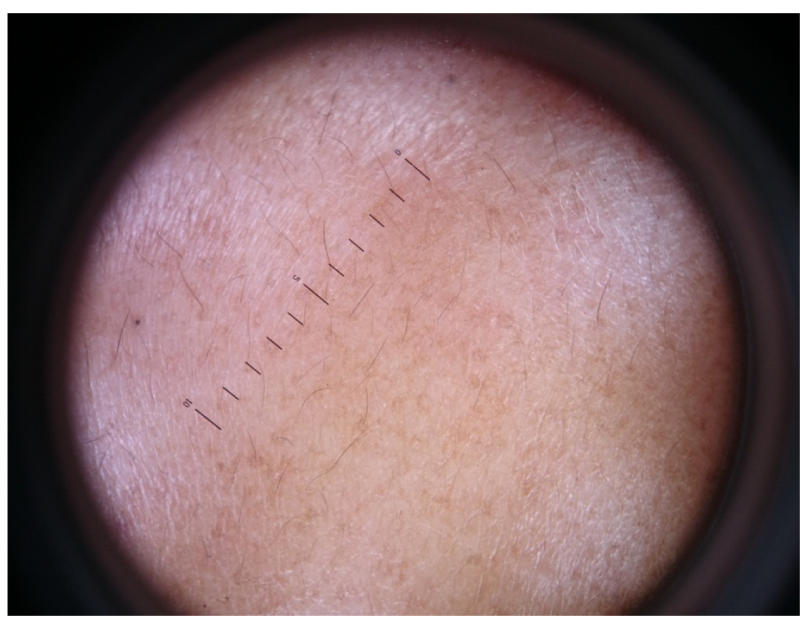

Figure I Dermoscopy of the study subject - representative image. Note: The dashed lines are the Dermoscope Instrument calibration.

reconfirmed by dermoscopic examination (Figure 1). Digital photographs were taken at baseline visit, intermediate visit at week 4 , and subsequent visit at week 8 . Along with this, the subjects' response to $4-n$-butylresorcinol $0.3 \%$ cream and side effects were evaluated.

\section{Subjects}

Subjects of both sexes, aged 18 years and above with Fitzpatrick skin types III, IV, and V having epidermal type of melasma were included in the study.

The subjects were either treatment naïve or had not been on any treatment for at least 6 months for melasma. Subjects were provided with sunscreen SPF (sun protection factor) 30 and were instructed to apply it during the entire course of the study. Written informed consent was obtained from all subjects prior to their participation and consent was also obtained for the use of the photos.

The exclusion criteria included subjects with dermal or any other type of melasma other than epidermal type, recent hormone or corticosteroid therapy, pregnancy, lactation, serious medical disorders, infectious skin disease, taking any other form of alternative treatment like ayurveda etc for melasma, subjects known to have hypersensitivity to any of the ingredients of the formulation.

The subjects who met the inclusion and exclusion criteria were given $4-n$-butylresorcinol $0.3 \%$ cream at the baseline visit. All the subjects were instructed to apply fingertip-unit amount of 4- $n$-butylresorcinol $0.3 \%$ cream twice daily on the face over the areas of melasma for 8 weeks. They were also advised to apply a broad-spectrum sunscreen. But, usage of any bleaching agent was not allowed during the study period.

\section{Assessment}

The diagnosis of epidermal melasma was done by Wood's light lamp examination and confirmed by Dermoscopy. All the recruited subjects visited the trial centers at baseline, week 4 , and week 8 .

The subjects were evaluated at the end of week 4 and week 8 for efficacy, safety, and tolerability based on the following objectives and outcomes.

Primary outcome was to evaluate the efficacy of 4- $n$-butylresorcinol in reducing melasma by comparing the modified Melasma Area Severity Index (mMASI) score at baseline ( 0 day) to follow-up visits at week-4 and 8 . In addition, digital photographs of the study subjects were taken at day 0 , week 4 , and week 8 for evaluation.

Secondary outcome was tolerability and safety assessment. Safety assessment was based on the adverse effects as mentioned by the patient and evaluated by the investigator. Tolerability was assessed by the investigators based on a 4-point scale as follows: excellent $=$ no adverse event reported; good $=$ mild adverse event(s) reported, which subsided with or without medication and did not necessitate stoppage of study medication; fair = moderate-to-severe adverse event(s) reported, which subsided with or without medication and did not necessitate stoppage of study medication; poor $=$ severe or serious adverse event(s), which necessitated stoppage of study medication.

\section{Modified Melasma Area Severity Index}

In this study, we used mMASI as published by Pandya et $\mathrm{al}^{9}$ to quantify the pigmentation area, darkness in patients with melasma. For assessing the hyperpigmented area of the face, four areas of face were evaluated (Table 2).

Melasma in each of the four areas (A) was given a numerical value: 1) $<10 \%$; 2) $10 \%-29 \%$; 3) $30 \%-49 \%$; 4) $50 \%-69 \%$; 5) $70 \%-89 \%$; and 6) $90 \%-100 \%$. Darkness of pigment compared with normal skin (D) was assessed in each area on a scale of 0 (absent) to 4 (severe).

To calculate the mMASI score, the following formula was used.

Table 2 mMASI scoring

\begin{tabular}{ll}
\hline Forehead $(F)$ & $30 \%$ \\
Right malar region (MR) & $30 \%$ \\
Left malar region (ML) & $30 \%$ \\
Chin (C) & $10 \%$ \\
\hline
\end{tabular}

Abbreviation: mMASI, modified Melasma Area Severity Index. 
Table 3 Demographic data of subjects $(\mathrm{N}=52)$

\begin{tabular}{ll}
\hline Characteristics & $\mathbf{N}(\%)$ \\
\hline Age (years) & $6(1 \mathrm{I} .5)$ \\
$20-30$ & $26(50)$ \\
$31-40$ & $18(34.6)$ \\
$4 I-50$ & $2(3.8)$ \\
$>50$ & $38.5 \pm 7.8$ \\
Mean age (years) & \\
Sex & $5(9.61)$ \\
Males & $47(90.38)$ \\
Females & \\
Occupation & $22(42.3)$ \\
Housewife & $16(30.7)$ \\
Students & $14(26.9)$ \\
Salaried employees
\end{tabular}

Note: Data are presented as mean \pm standard deviation.

$$
\begin{aligned}
\operatorname{mMASI} \text { score }= & \text { forehead }(0.3)(\mathrm{A})(\mathrm{D}) \\
& + \text { left malar }(0.3)(\mathrm{A})(\mathrm{D}) \\
& + \text { right malar }(0.3)(\mathrm{A})(\mathrm{D}) \\
& +\operatorname{chin}(0.1)(\mathrm{A})(\mathrm{D})
\end{aligned}
$$

\section{Statistics}

The data were analyzed using repeated measures of analysis of variance (ANOVA) using SPSS version 16.0 (SPSS Inc., Chicago, IL, USA). The results are considered statistically significant whenever $P \leq 0.05$. For the primary efficacy variable mMASI score, mean and standard error were calculated. The repeated measures of ANOVA (rANOVA) were used to test changes that have taken place from baseline to week 8 . The post hoc test was used to compare between baseline value and week 4 as well as week 4 and week 8 follow-up value of mMASI score.

\section{Results}

A total of 52 subjects were recruited into the study. No subjects were lost to follow-up. All subjects were protocol compliant. Table 3 shows the demographic data of subjects. Out of 52 subjects, majority were women $(90.38 \%)$. Approximately $42.3 \%$ of the subjects were housewives. Nearly half of the study subjects were aged between 31 and 40 years. The mean age of subjects was $38.5 \pm 7.8$ years.

Primary outcome assessment showed a significant decrease in the mean mMASI score $(-3.64)$ after 4 weeks

Table 4 The changes in the mMASI score

\begin{tabular}{lllll}
\hline MASI score & N & Mean \pm SE & F-value & P-value \\
\hline Baseline & 52 & $14.73 \pm 0.59$ & 180.729 & $<0.00 \mathrm{I}$ \\
Week 4 & 52 & $11.09 \pm 0.53$ & & \\
Week 8 & 52 & $6.48 \pm 0.43$ & & \\
\hline
\end{tabular}

Abbreviations: mMASI, modified Melasma Area Severity Index; SE, standard error.

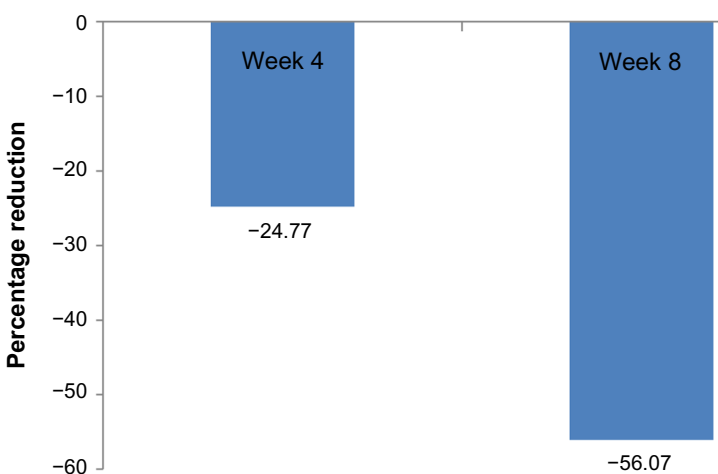

Figure 2 Percentage reduction in mMASI score from baseline. Abbreviation: mMASI, modified Melasma Area Severity Index.

of 4- $n$-butylresorcinol therapy. Furthermore, a statistically significant decrease (-8.25) was observed in mMASI score after 8 weeks in 4 - $n$-butylresorcinol-treated skin in comparison to baseline score. As shown in the Table 4, mean \pm standard error of MASI score measurements decreased from baseline score of $14.73 \pm 0.59$ to $11.09 \pm 0.53$ and $6.48 \pm 0.43$ after week $4(P<0.001)$ and week $8(P<0.001)$, respectively.

It was observed from this study that there was a gradual reduction in the mMASI score measured at three different time points, namely, baseline, week 4 , and week 8 , which was found to be highly statistically significant $(P<0.001)$ using rANOVA. There was a percentage change of 56.07 in the mean mMASI score during the 8-week study period as shown in Figure 2.

The mean mMASI score of various age groups was evaluated (Table 5). There was no statistical difference of response between the various age groups.

Furthermore, the mean mMASI score difference at week 4 and week 8 from baseline visit between men and women was evaluated (Figure 3), and it was found that the difference was statistically not significant between the sexes.

Digital photograph evaluation of all the study subjects was done at baseline, week 4 , and week 8 of the study to assess treatment outcome. Figure 4 shows the representative

\begin{tabular}{|c|c|c|c|c|c|}
\hline Age (years) & Baseline $^{a}$ & Week $4^{a}$ & Week $8^{a}$ & $F$-value & $P$-value \\
\hline$\leq 30(n=6)$ & $13.4 \mathrm{I} \pm \mathrm{I} .25$ & $10.03 \pm 1.11$ & $6.26 \pm 0.69$ & 21.063 & $<0.001$ \\
\hline $31-40(n=26)$ & $14.56 \pm 1.13$ & I I.03 0.84 & $6.55 \pm 0.68$ & 59.015 & $<0.001$ \\
\hline $4 \mid-50(n=18)$ & $15.42 \pm 0.76$ & $11.42 \pm 0.89$ & $6.28 \pm 0.66$ & 82.580 & $<0.001$ \\
\hline$>50(n=2)$ & $14.86 \pm 1.67$ & I I.62 62.33 & $7.18 \pm 2.47$ & 19.876 & $<0.001$ \\
\hline
\end{tabular}
digital photographs with the gradual reduction in the mMASI score with $4-n$-butylresorcinol $0.3 \%$ cream use.

Table 5 Mean mMASI score for various age groups

Note: a Mean \pm SE.

Abbreviations: mMASI, modified Melasma Area Severity Index; SE, standard error. 


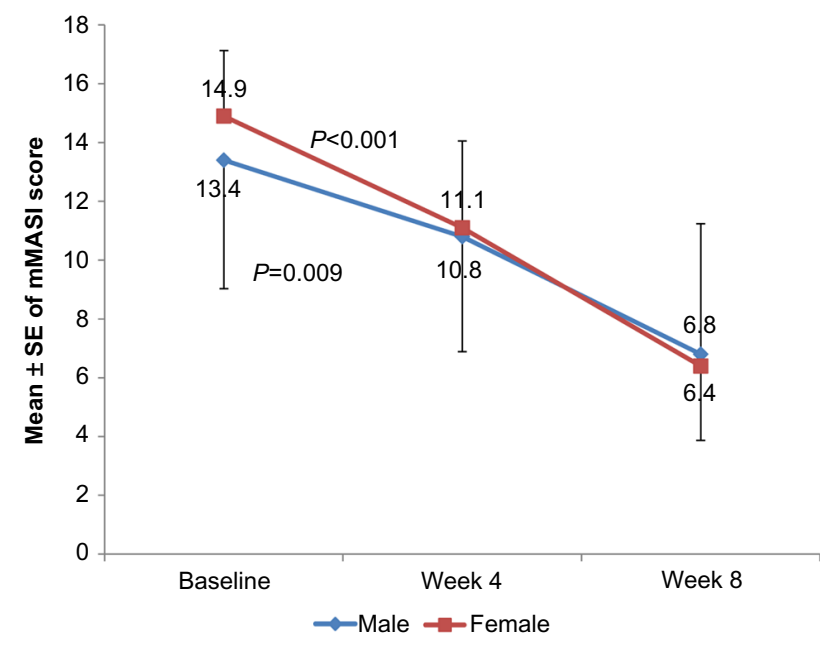

Figure 3 mMASI score for sex.

Abbreviations: mMASI, modified Melasma Area Severity Index; SE, standard error.
The post hoc test revealed that the change from baseline to week 4 as well as from week 4 to week 8 was also highly statistically significant (Table 6).

During the 8-week study period, no adverse events related to study medication were experienced by the patients nor were any adverse events observed by the investigators. 4- $n$-Butylresorcinol was well tolerated, and all the subjects were highly satisfied with the treatment.

\section{Discussion}

Melasma is the commonly reported, distressing skin disorder, which is often therapeutically challenging. ${ }^{6}$ Tyrosinase is a key enzyme in melanogenesis, and inhibition of its activity is the effective way to prevent hyperpigmentation.

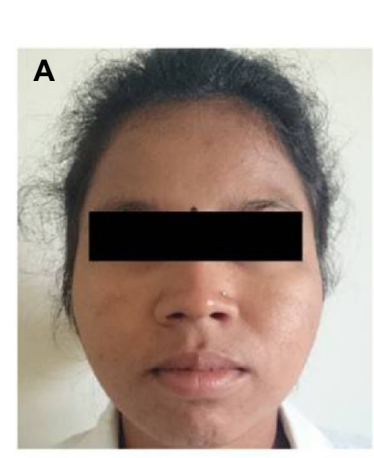

Baseline

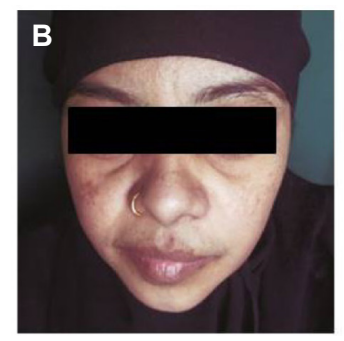

Baseline

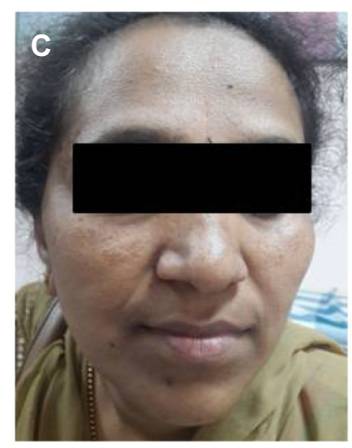

Baseline

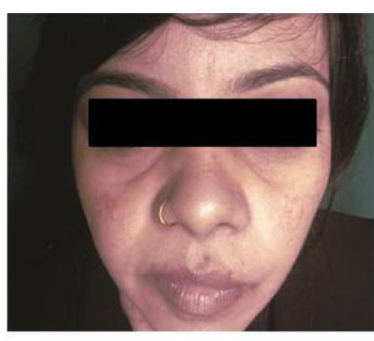

Week 4

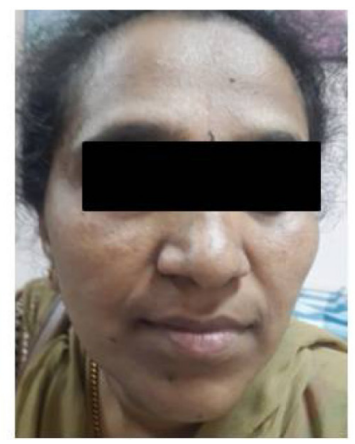

Week 4

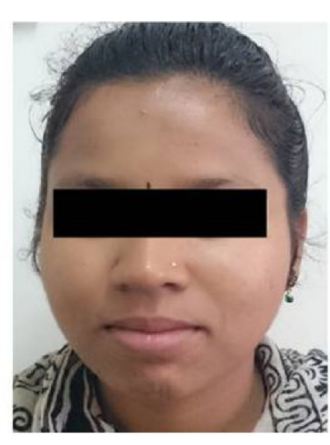

Week 8

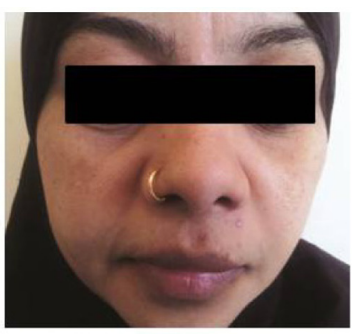

Week 8

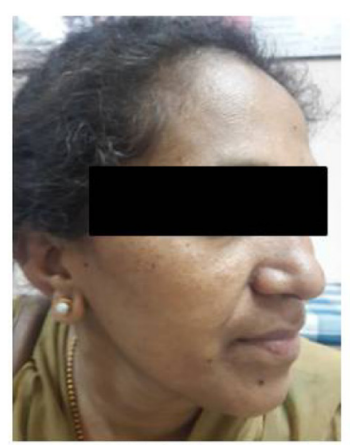

Week 8

Figure 4 Improvements in melasma.

Note: Representative images of study subjects $(\mathbf{A}-\mathbf{C})$ at baseline visit, week 4 , and week 8 . 
Table 6 Post hoc test

\begin{tabular}{lllll}
\hline Number & $\begin{array}{l}\text { Pairwise comparison } \\
\text { of MASI score }\end{array}$ & Mean \pm SE & F-value & P-value \\
\hline $\mathrm{I}$ & Baseline & $14.73 \pm 0.59$ & 80.457 & $<0.00 \mathrm{I}$ \\
& Week 4 & $11.09 \pm 0.53$ & & \\
2 & Week 4 & $11.09 \pm 0.53$ & $149.57 \mathrm{I}$ & $<0.00 \mathrm{I}$ \\
& Week 8 & $6.48 \pm 0.43$ & & \\
\hline
\end{tabular}

Abbreviations: MASI, Melasma Area Severity Index; SE, standard error.

According to the published literature, hydroquinone is considered as the gold standard in the management of hyperpigmentation. However, safety of hydroquinone in this subset of patients has raised severe concern. Arbutin is a hydroquinone prodrug, and its tyrosinase inhibitory activity is attributed to hydroquinone release from the molecule and thus shares the same safety concern as hydroquinone therapy. Regarding kojic acid, in vivo studies show it to have a very limited efficacy. ${ }^{10,11}$

4- $n$-Butylresorcinol, the newer hypopigmenting agent, inhibits both tyrosinase and TRP-1. Superior human tyrosinase inhibitory activity of 4- $n$-butylresorcinol versus hydroquinone, arbutin, and kojic acid has been established in biochemical assays. ${ }^{10,11}$

Clinical studies on 4-n-butylresorcinol have demonstrated its effectiveness in the management of hyperpigmentation. In a placebo-controlled clinical trial by Akasaka et a ${ }^{12}$ use of 4- $n$-butylresorcinol $0.3 \%$ serum for 18 weeks resulted in good improvement in subjects with postlaser pigmented lesions. ${ }^{12}$ In an open-label study on 4- $n$-butylresorcinol $0.3 \%$ serum in patients with melasma, at 24 -week evaluation, $84 \%$ of the patients showed good response to treatment. ${ }^{13}$

In a double-blind, randomized, split-face study by Khemis et al, ${ }^{14} 4-n$-butylresorcinol $0.3 \%$ serum was associated with significant clinical outcomes. This vehiclecontrolled study involved 28 melasma patients, and the outcomes were evaluated based on clinical correlation and colorimetric measurements after 12 weeks of therapy. ${ }^{14}$ The clinical improvements in skin hyperpigmentation in various studies reveal 4- $n$-butylresorcinol as a very valuable active compound for the management of pigmentation disorders. In view of its efficacy, we explored the efficacy, safety, and tolerability of 4- $n$-butylresorcinol in Indian patients with melasma, as there is paucity of Indian studies on 4-n-butylresorcinol.

In our study, $4-n$-butylresorcinol $0.3 \%$ cream was very effective and resulted in good clinical outcomes, which were statistically significant after 4 weeks, and a clinically significant gradual reduction in the mMASI score was recorded even at the end of study at 8 weeks. The decrease in mMASI score at week 4 and at week 8 in comparison to baseline was highly statistically significant $(P<0.001)$. At the end of 8 -week study, the mean mMASI score change $(-56.07 \%)$ was statistically significant $(P<0.001)$. 4- $n$-Butylresorcinol $0.3 \%$ cream was very well tolerated by all the study subjects, and there were no adverse events reported.

\section{Conclusion}

4- $n$-butylresorcinol $0.3 \%$ cream is an effective addition to the therapeutic armamentarium for the management of melasma in Indian population, with good safety, efficacy, and tolerability.

The limitation of the study is that it had an open-label design and no control group. To overcome this limitation, we propose conducting a double-blind, randomized comparative study in future.

\section{Disclosure}

Manjula Shamanna is an employee of Micro Labs Ltd which manufactures $4-n$-butylresorcinol $0.3 \%$ cream (ONETONE cream). The authors report no other conflicts of interest in this work.

\section{References}

1. Bandyopadhyay D. Topical treatment of melasma. Indian J Dermatol. 2009;54(4):303-309.

2. Pasricha JS, Khaitan BK, Dash S. Pigmentary disorders in India. Dermatol Clin. 2007;25:343-522.

3. Vázquez M, Maldonado $\mathrm{H}$, Benmamán $\mathrm{C}$, et al. Melasma in men. A clinical and histologic study. Int J Dermatol. 1988;27:25-27.

4. Grimes PE, Yamada N, Bhawan J. Light microscopic, immunohistochemical, and ultrastructural alteration in patients with melasma. Am J Dermatopathol. 2005;27:96-101.

5. Kang WH, Yoon KH, Lee ES, et al. Melasma: histopathological characteristics in 56 Korean patients. Br J Dermatol. 2002;146:228-237.

6. Huh SY, Shin JW, Na JI, et al. The efficacy and safety of 4-n-butylresorcinol $0.1 \%$ cream for the treatment of melasma: a randomized controlled split-face trial. Ann Dermatol. 2010;22(1):21-25.

7. Okubo T, Oyohikawa M, Futaki K, et al. The inhibitory effects of 4-N-butyl-resorcinol on melanogenesis [abstract]. J Dermatol Sci. 1995; $10: 88$.

8. Lev-Tov H, Maibach HI. The sensitive skin syndrome. Indian J Dermatol. 2012;57(6):419-423.

9. Pandya AG, Hynan LS, Bhore R, et al. Reliability assessment and validation of the Melasma Area and Severity Index (MASI) and a new modified MASI scoring method. J Am Acad Dermatol. 2011;64(1):78-83; 83. $\mathrm{e} 1-\mathrm{e} 2$.

10. Kolbe L, Mann T, Gerwat W, et al. 4-n-butylresorcinol, a highly effective tyrosinase inhibitor for the topical treatment of hyperpigmentation. J Eur Acad Dermatol Venereol. 2013;27(Suppl 1):19-23.

11. Briganti S, Camera E, Picardo M. Chemical and instrumental approaches to treat hyperpigmentation. Pigment Cell Res. 2003;16:101-110. 
12. Akasaka T, Ohurazaka H, Nishioheda G, et al. Topically applied $0.3 \%$ 4-n-butylresorcinol decreases pigmentation after laser therapy. Environ Dermatol. 2002;9:11-15.

13. Researching committee of Rucinol ${ }^{\circledR}$. The study on the efficacy of Rucinol $^{\circledR}$ (4-n-butylresorcinol) in chloasma. Nishinihon J Dermatol. 1999;61:813-819.

14. Khemis A, Kaiafa A, Queille-Roussel C, et al. Evaluation of efficacy and safety of rucinol serum in patients with melasma: a randomized controlled trial. Br J Dermatol. 2007;156:997-1004.
15. Nicolaidou E, Antoniou C, Katsambas AD. Origin, clinical presentations, and diagnosis of facial hypermelanosis. Dermatol Clin. 2007;25:321-326.

16. Katsambas A, Antoniou C. Melasma: classification and treatment. J Eur Acad Dermatol Venereol. 1995;4:217-223.

17. Hann SK, Im S, Chung WS, et al. Pigmentary disorders in the South East. Dermatol Clin. 2007;25:431-438.

\section{Publish your work in this journal}

Clinical, Cosmetic and Investigational Dermatology is an international, peer-reviewed, open access, online journal that focuses on the latest clinical and experimental research in all aspects of skin disease and cosmetic interventions. All areas of dermatology will be covered; contributions will be welcomed from all clinicians and basic science researchers globally. This journal is indexed on CAS. The manuscript management system is completely online and includes a very quick and fair peer-review system, which is all easy to use. Visit http://www.dovepress.com/testimonials.php to read real quotes from published authors.

Submit your manuscript here: http://www.dovepress.com/clinical-cosmetic-and-investigational-dermatology-journal 